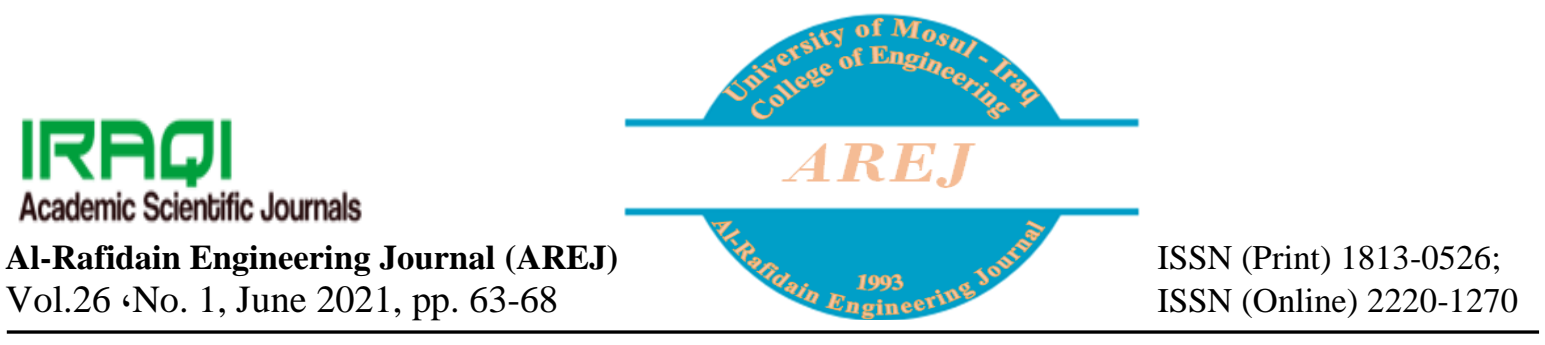

\title{
Hydraulic Properties Downstream Multi-Opened Sluice Gate
}

\author{
Mohammad Y. Hamid* \\ mohammad74Qattan@uomosul.edu.iq \\ Ahmed Y. Mohammed** \\ a.altaee@uomosul.edu.iq \\ * Building \& Construction Technical Engineering Department, Technical Engineering Collage, \\ Northern Technical University \\ ${ }^{* * *}$ Dams and Water Resources Engineering Department, Collage of Engineering, University of Mosul
}

Received: 14/5/2020

Accepted: 6/10/2020

\begin{abstract}
:
In this paper four gate openings and fifteen operating scenarios in terms of the difference in the arrangement of working gates were studied. The Expansion Ratio (e) which is (the ratio of total width of the channel to the total width of the working gates) was calculated for each scenario. It can be seen that when the value of (e) was the largest possible, which is (5.34), the value of the discharge coefficient (Cd) was also as high as possible, reached to (0.845). Also, the value of the contraction coefficient (Cc) was the highest value, (0.693). The increasing in the value of (e) means that the number of openings that work is less. Both $(C d)$ and $(C c)$ are decreases when Froude Number increased for all scenarios of gate worked operations.
\end{abstract}

\section{Keywords:}

Multi-open gates; Expansion Ratio; Coefficient of discharge; Coefficient of contraction.

https://rengj.mosuljournals.com

Email: alrafidain_engjournal@umosul.edu.iq

\section{INTRODUCTION}

A sluice gate is an adjustable plate that can be opened or closed by sliding in supporting guides, which can be used to measure flow, as this hydraulic structure has an easy design and high durability. There are some characteristics of flow at gates that have been studied as they are considered important for hydraulic researchers, including the calculation of the expansion ratio at the gate and its effect on the discharge coefficient and contraction coefficient, as well as the energy loss factor and its effect on the discharge coefficient. Many studies dealt with sluice gate from several sides such as; Swamee [1] which calculated the practical discharge coefficient from the curves drawn between the discharge coefficient and both the water level at the upstream and the gate opening for free flow and between the discharge coefficient and the tail water depth of submerged flow. Bagheri [2] developed an equation to calculate the discharge coefficient using potential flow and conducted 84 laboratory experiments to derive this equation and compared the discharge coefficient values obtained from practical experiments with their counterparts calculated from the equation and obtained good results for comparison. Mohammad and Hayawi [3] studied the characteristics of the hydraulic jump and energy dissipation at the downstream of the sluice gate for variable gate openings. It turns out that the energy dissipation in hydraulic jump depends on Froude Number, Weber Number and amount of gate opening. They concluded that energy dissipation decreases with an increase in Weber Number, and if gate opening decrease, Weber Number will increase. And that the energy dissipation increases with the increase of Froude Number, and Froude Number decrease with the increase in the amount of the gate opening. Mohammad and Khalil [4] presented a study on the effect of five states in shape of edge of the lower of gate and its slope in the form of flow surface, at variable gate openings, and five upstream levels. The researchers concluded that the state of the inclined gate against the direction 
of flow gave the lowest flow surface, while the slanted gate toward the flow gave the highest distance to the flow surface. Osoku and Salimasi [5] devised linear and non-linear equations to calculate the discharge coefficient using linear and non-linear regression analysis in free and submerged flow at the gate. Whereas, the nonlinear equation performed better than the linear equation. Mohammad and Khalil [6] tested the effect of five states on the level of the lower edge of one-open gate and the angle of the gate slope on contraction, discharge, and velocity coefficients, for different discharges and a variable gate opening, they concluded that the value of both contraction coefficient $(\mathrm{Cc})$ and discharge coefficient (Cd) increase with increasing slope of the gate towards the direction of flow and at the horizontal edge level, and it decreased with the slope of the gate against the flow direction with horizontal plane of the lower edge. The study showed that velocity coefficient (Cv) was not affected and its value remained constant. Shayan and Farhoudi [7] conducted a study to show the flow characteristics of dam gates under free-flowing and submerged conditions using energy and momentum eqs. (EMEs). An equation was developed to estimate the energy loss coefficient of the gates in freeflow, and the effect of this factor on increasing the accuracy of the discharge coefficient was shown. Sauida [8] studied factors affecting the discharge of multi-gate submersible dams, such as the expansion ratio and others, using the regression analysis of results, an improved discharge coefficient equation was obtained, the study showed that the increase in expansion ratio and asymmetric operation of gates gave high values of discharge coefficient. Malumbassi et al. [9] studied calculating the value of gate discharge coefficient by testing the two-open gate in freeflow conditions. He concluded that if the gate is open and the upstream water level of the gate is fixed, then the discharge coefficient will be directly proportional to the discharge of the gate. Sunick [10] studied energy dissipation using cubic baffles in different sides with sills in different heights, the aim is to obtain the best value for the coefficient of determination $\left(\mathrm{R}^{2}\right)$ for the relationship of contraction coefficient $(\mathrm{Cc})$ and discharge coefficient $(\mathrm{Cd})$ with Froude number (Fr) with variable discharges and different openings.

The present work includes testing the effect of changing the gate operating scenario for four opening sluice gate with different levels on the discharge coefficient $(\mathrm{Cd})$ and contraction coefficient $(\mathrm{Cc})$

\section{EXPERIMENTAL METHODOLOGY:}

Laboratory experiments were conducted in the hydraulic laboratory of the Dams and Water Resources Department - College of Engineering University of Mosul, In rectangular channel, $18 \mathrm{~m}$ long, $80 \mathrm{~cm}$ wide and $70 \mathrm{~cm}$ depth, The structure of the gates was made of transparent plastic with a thickness of $6 \mathrm{~mm}$, the structure is $80 \mathrm{~cm}$ wide and $70 \mathrm{~cm}$ high, consisting of four plastic slides with a thickness of $3 \mathrm{~mm}$ and a net width of 15 $\mathrm{cm}$ and a height of $70 \mathrm{~cm}$ and listed from the sides to measure the size of the gate opening, as shown in the figure (1), placed at a distance of 9 meters from the entrance to the channel.

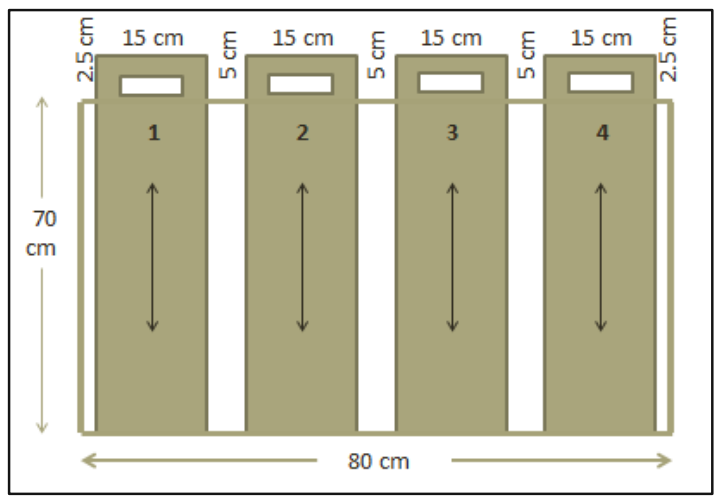

Fig. (1): An illustration of the four gates

Figure (2) shows a side view of the gate and the free flow condition at the gate. Figure (3) shows an upper view of the gate with multiple openings.

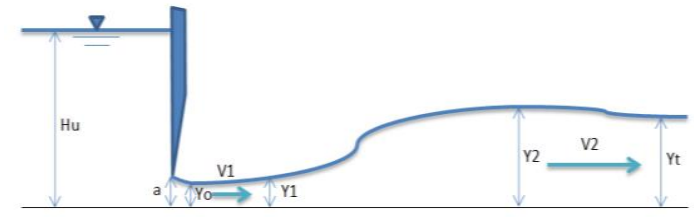

Fig. 2 Side view of the gate and the free flow condition

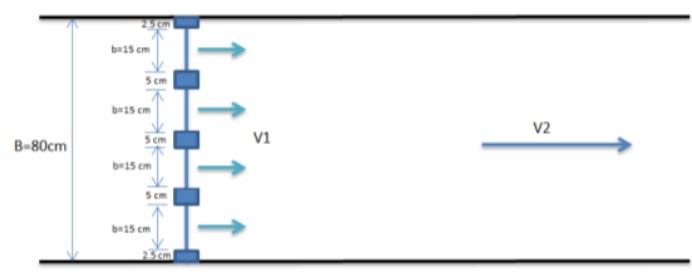

Fig. 3 Upper view of the gate with multiple openings

Fifteen operating scenarios were conducted, the first scenario, all four gates were opened 
$(1+2+3+4)$. The second to fifth scenarios, three gates were opened in sequence $(1+2+3),(1+2+4)$, $(2+3+4)$ and $(1+3+4)$. The sixth to eleventh scenarios, two gates were opened as the following $(1+2),(1+3),(1+4),(2+3),(2+4)$ and $(3+4)$. The last four scenarios, single gate was opened in order (1), (2), (3) and (4). It's worth to mention that the gate opening for all previous scenarios is fixed at $4 \mathrm{~cm}$ and the water at the upstream side of the gate was with the following depths $(15,20$, $25,30$ and 35$) \mathrm{cm}$.

\section{THEORETICAL METHODOLOGY:}

The actual discharge of laboratory experiments was measured by a sharp edge rectangular weir it is $0.8 \mathrm{~m}$ wide and $0.15 \mathrm{~m}$ depth. It is fixed at the end of the channel made of plastic Per Plax, $10 \mathrm{~mm}$ thick, used British standard specifications (British Standard No. 3680: Part 4A: 1965) [11] in the discharge calculations in eq.(1)

$Q_{\text {act. }}=\frac{2}{3} \sqrt{2 g} C_{e} w_{e} h_{e}^{1.5}$ where, $Q_{a c t}$ is the actual discharge in channel, $\mathrm{w}_{e}$ is the effective width of the weir, he is the effective height of the weir and $C_{e}$ is the discharge coefficient that calculated from eq. (2)

$$
C_{e}=0.602+0.075 \frac{H w}{P}
$$

where, $H w$ is the height of water measured from the edge of weir, $P$ is the weir height. The effective width of the weir is calculated from eq. (3)

$w_{e}=w+k_{w}$

where, $\mathrm{w}$ is the width of the weir, $k w$ is equal (-0.001). The effective height of the weir he can calculated from eq. (4)

$h_{e}=H w+K_{h}$

where, $\mathrm{K}_{h}$ is (0.001). Finally, after compensating for the values of $\mathrm{Ce}$, we, and he in eq. (1), then the weir discharge formula became

$$
Q_{\text {act. }}=2.35942(0.602+0.5 H w)(H w+0.001)^{1.5}
$$

The measured and computed values are shown in table 1.

Table 1: Sample of experimental measurements and calculations

\begin{tabular}{||c|c|c|c||c|c||c||c||c||c||}
\hline $\begin{array}{c}\mathrm{Hu} \\
(\mathrm{cm})\end{array}$ & $\begin{array}{c}\text { No. of } \\
\text { gates }\end{array}$ & $\mathrm{e}$ & $\begin{array}{c}\mathrm{y}_{\mathrm{o}} \\
(\mathrm{m})\end{array}$ & $\begin{array}{c}\mathrm{y}_{1} \\
(\mathrm{~m})\end{array}$ & $\begin{array}{c}\mathrm{Q}_{\mathrm{act}} \\
\left(\mathrm{m}^{3} / \mathrm{s}\right) .\end{array}$ & $\mathrm{Fr} 1$ & $\begin{array}{c}\mathrm{Q}_{\mathrm{th}} \\
\left(\mathrm{m}^{3} / \mathrm{s}\right)\end{array}$ & $\mathrm{Cd}$ & $\mathrm{Cc}$ \\
\hline \hline 35 & 4 & 1.34 & 0.025 & 0.015 & 0.0419 & 9.104 & 0.061 & 0.691 & 0.613 \\
\hline 30 & 4 & 1.34 & 0.025 & 0.017 & 0.0405 & 7.287 & 0.057 & 0.716 & 0.625 \\
\hline 25 & 4 & 1.34 & 0.026 & 0.019 & 0.0377 & 5.738 & 0.051 & 0.737 & 0.650 \\
\hline 20 & 4 & 1.34 & 0.026 & 0.017 & 0.0310 & 5.734 & 0.042 & 0.742 & 0.650 \\
\hline 15 & 4 & 1.34 & 0.027 & 0.016 & 0.0291 & 5.730 & 0.039 & 0.747 & 0.675 \\
\hline \hline 35 & 3 & 1.78 & 0.025 & 0.016 & 0.0342 & 6.823 & 0.045 & 0.753 & 0.615 \\
\hline 30 & 3 & 1.78 & 0.025 & 0.018 & 0.0313 & 5.407 & 0.041 & 0.760 & 0.636 \\
\hline 25 & 3 & 1.78 & 0.026 & 0.018 & 0.0266 & 4.583 & 0.035 & 0.770 & 0.656 \\
\hline 20 & 3 & 1.78 & 0.026 & 0.016 & 0.0230 & 4.441 & 0.029 & 0.781 & 0.656 \\
\hline 15 & 3 & 1.78 & 0.027 & 0.017 & 0.0225 & 4.118 & 0.029 & 0.793 & 0.675 \\
\hline \hline 35 & 2 & 2.67 & 0.025 & 0.012 & 0.0213 & 6.510 & 0.028 & 0.754 & 0.625 \\
\hline 30 & 2 & 2.67 & 0.026 & 0.013 & 0.0197 & 5.028 & 0.026 & 0.771 & 0.640 \\
\hline 25 & 2 & 2.67 & 0.026 & 0.015 & 0.0202 & 4.338 & 0.026 & 0.785 & 0.652 \\
\hline 20 & 2 & 2.67 & 0.027 & 0.015 & 0.0186 & 4.177 & 0.023 & 0.815 & 0.667 \\
\hline 15 & 2 & 2.67 & 0.027 & 0.014 & 0.0122 & 3.971 & 0.015 & 0.830 & 0.673 \\
\hline \hline 35 & 1 & 5.34 & 0.025 & 0.017 & 0.0113 & 2.406 & 0.015 & 0.745 & 0.625 \\
\hline 30 & 1 & 5.34 & 0.026 & 0.017 & 0.0104 & 2.263 & 0.014 & 0.798 & 0.650 \\
\hline 25 & 1 & 5.34 & 0.027 & 0.016 & 0.0096 & 1.900 & 0.012 & 0.820 & 0.663 \\
\hline 20 & 1 & 5.34 & 0.027 & 0.016 & 0.0072 & 1.531 & 0.009 & 0.840 & 0.675 \\
\hline 15 & 1 & 5.34 & 0.028 & sub. & 0.0021 & 1.420 & 0.003 & 0.845 & 0.694 \\
\hline \hline
\end{tabular}


In table 1 , the arithmetic mean value of discharge was adopted for the scenarios of three gates, two gates and one gate opening.

The theoretical discharge, discharge coefficient $\mathrm{Cd}$ and contracting coefficient $\mathrm{Cc}$ can calculate from the following equations, $[12,13]$.

$$
\begin{aligned}
& Q_{t h}=a * b * n * \sqrt{2 g\left(H_{u}-y_{o}\right)} \\
& C_{d}=\frac{Q_{\text {act }} .}{Q_{\text {th }} .} \\
& C_{c}=\frac{y_{o}}{a}
\end{aligned}
$$

Where $\left(y_{o}\right)$ is the water depth at the vena contracta, and $(a)$ is the gate opening height. The expansion ratio (e) is calculated from the following equation [3]:

$$
e=\frac{B}{b_{t}}
$$

Where:

$$
b_{t}=b * n
$$

Where $\left(b_{t}\right)$ is the total widths of the opened gates, $(b)$ is the width of the opened gate and $(n)$ is the number of the opened gates.

\section{RESULTS AND DISCUSSIONS}

Figure (3) shown that the highest value of discharge coefficient $(\mathrm{Cd}=0.84)$ at highest value of expansion ratio $(\mathrm{e}=5.34)$ and the lowest value of the Froude Number $(\operatorname{Fr} 1=1.53)$, while the value of $\mathrm{Cd}$ is lowest value (0.69) at the lowest value for (e) (1.34) and the highest value for Fr1 (9.1), because when $(e=1.53)$, means that the four openings work simultaneously and the discharge is as high as possible, and to maintain a constant level at the upstream of gate increases the discharge whenever an additional gate is opened, and that increases of discharge means an increases in the average velocity and thus an increases Fr1.

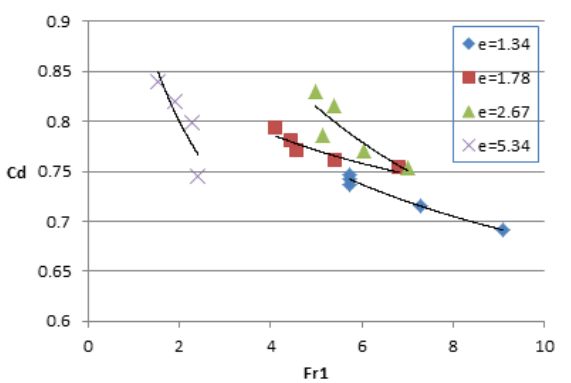

Fig. 3 Relationship between Fr1 and Cd for different values of expansion ratio
The value of the discharge coefficient (Cd) decreases by increasing the water level at the upstream of the gate, where it was the lowest possible at the level $(35) \mathrm{cm}$, and the highest possible at the level (15) $\mathrm{cm}$, because lowering the water level upstream of the gate means less discharge passing through it, thus increasing the value of the discharge coefficient $(\mathrm{Cd})$ and vice versa, as in Figure (4).

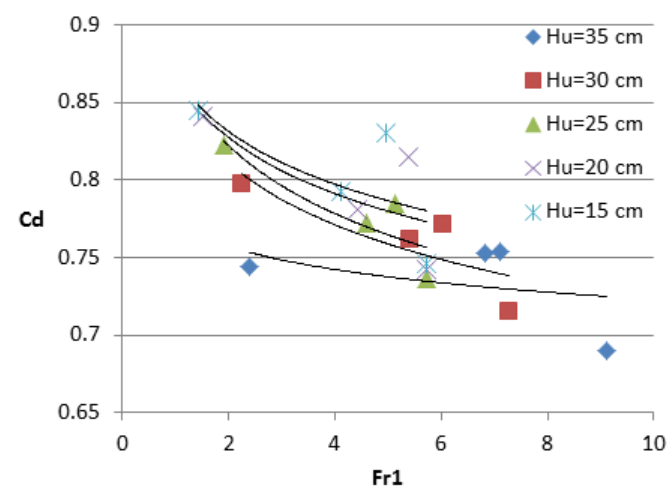

Fig. 4 Relationship between Fr1 and Cd for variable upstream level

Figure (5) shown, the highest value of the contraction coefficient $(\mathrm{Cc}=0.69)$ at highest value expansion ratio $(e=5.34)$ and the lowest value of Froude Number $(\operatorname{Fr} 1=1.42)$ and the value of the contraction coefficient is the lowest possible $(\mathrm{Cc}=0.6125)$ at the lowest value for the expansion ratio $(e=1.34)$ and the highest value of Froude Number (Fr1=9.1), and the same for other expansion ratio values (2.67) and (1.78).

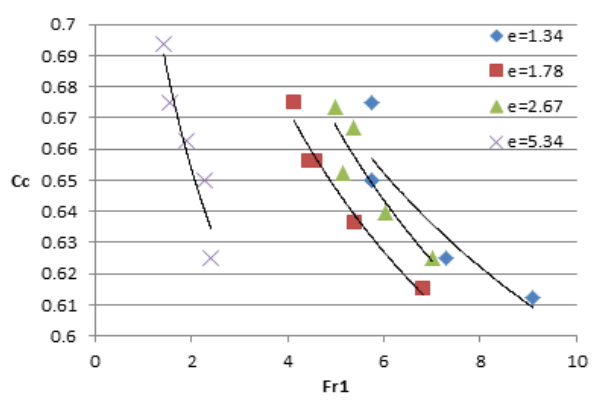

Fig. 5 Relationship between Fr1 and Cc for different values of expansion ratio

The value of the contraction coefficient (Cc) decreases by increasing the water level at the upstream of the gate, where it was the lowest possible at the level (35) $\mathrm{cm}$, and the highest 
possible at the level $(15) \mathrm{cm}$, because at the high depths, the discharge is high as well as the average velocity is high and Fr1 is high too and therefore a lower value for $(\mathrm{Cc})$ as shown in Figure (6)

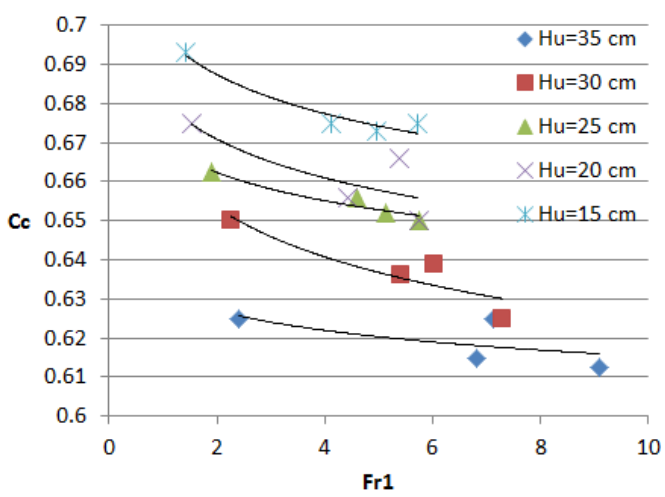

Fig. 6 Relationship between Fr1 and Cc for variable upstream level

\section{CONCLUSION}

The characteristics of free flow were clarified and discussed by relying on laboratory experiments, where it was found that the discharge coefficient $(\mathrm{Cd})$ is affected by the value of the expansion ratio (e). The value of the discharge coefficient (Cd) increases with increasing the value of the expansion ratio (e) for different water levels at the upstream of the gate.

The value of the contraction coefficient (Cc) was also greatest when the expansion ratio was at the highest value and has a minimum number of Froude, as it is affected by the average velocity of flow at the gates.

The value of both the discharge and the contraction coefficients decreases by increasing both the depth upstream the gate and Froude Number.

\section{ACKNOWLEDGEMENTS}

The authors thanked the staff of Hydraulic Laboratory in Dams and Water Resources Department, College of Engineering to assistance completed this research.

\section{NOTATIONS}

$Q_{t h}$ theoretical discharge $\left(\mathrm{m}^{3} / \mathrm{sec}\right)$

$Q_{A C \text { i }}$ actual discharge $\left(\mathrm{m}^{3} / \mathrm{sec}\right)$

$H_{U}$ upstream water depth (m)

$C_{d}$ discharge coefficient (-)

$C_{c}$ contraction coefficient (-)

\section{REFERENCES} equations," Journal of Irrigation and Drinage
Engineering, vol. 118, no. 1, pp. 56-60, 1992. S. Bagheri, "Briefing: Discharge coefficient for sluice gates," Proceedings of the Institution of Civil Engineers, Water Management 163, paper 900051, no. October, pp. 435-438, 2010.

[3] H. A. Hayawi and A. Y. Mohammed, "Properties of Hydraulic Jump Down Stream Sluice Gate," Research Journal of Applied Sciences, Engineering and Technology 3(2): 81-83, 2011.

[4] A. Y. Mohammed and M. S. Khaleel, "The Effect of a Sluice Gate Edge on Water Surface Profile," Journal of Civil Engineering and Urbanism (JCEU), vol. 2, no. 6, pp. 239-243, 2012.

[5] N. N. Oskuyi and F. Salmasi, "Vertical Sluice Gate Discharge Coefficient," Journal of Civil Engineering and Urbanism (JCEU), vol. 2, no. 3, pp. 108-114, 2012.

[6] A. Y. Mohammed and M. S. Khaleel, "Gate Lip Hydraulics under Sluice Gate," Modern Instrumentation, 2013， 2， 16-19 http://dx.doi.org/10.4236/mi.2013.21003.

[7] H. K. Shayan and J. Farhoudi, "Effective parameters for calculating discharge coeffi cient of sluice gates," Flow Meas. Instrum., vol. 33, pp. 96-105, 2013.

[8] M. F. Sauida, "Calibration of submerged multi-sluice gates," Alexandria Engineering Journal, pp. 663-668, 2014.

[9] A. Mallombassi, M. Bisri, P. T. Juwono, and R. Musa, "Modeling of Sluice Gate Operational Patterns with Two Openings and Free Flow Condition in Retention Ponds as Flood Controllers ," IOSR Journal of Engineering (IOSRJEN), vol. 9, no. 6, pp. 3143, 2019.

[10] S. Sunik, "Modelling Equation of Contraction Coefficient ( $\mathrm{Cc}$ ) and Discharge Coefficient ( $\mathrm{Cd}$ ) for Flow under Sluice Gate Using Cubic Baffle Block and Sill," Intrenational Journal of Applied Engineering Research, vol. 14, no. 14, 
pp. 3155-3158, 2019.

[11] British Standard Institution (BSI), "Method of Measurement of Liquid Flow in Open Channel", Part 4A.BSI, 3680, London, English, U.K., (1965).
[12] R. K. Bansal, "A Textbook of Fluid Mechanics and Hydraulic Machines.”,(2010).

[13] F. M. Henderson, "Open Channel Flow." Macmillan Pubhishing Co. Inc., pp. 273, 1966.

\section{خصائص الجريان مؤخر البوابة متعددة الفتحات}

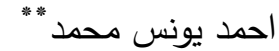

a.altaee@uomosul.edu.iq

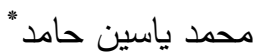

mohammad74Qattan@uomosul.edu.iq

*قتم هندسة تقنيات البناء و الانثاءات، الكلية التقنية الهندسية، الجامعة التقنية الثمالية

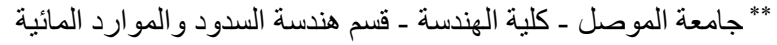

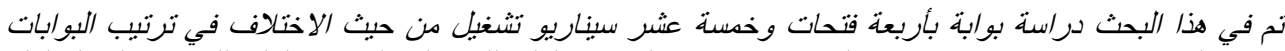

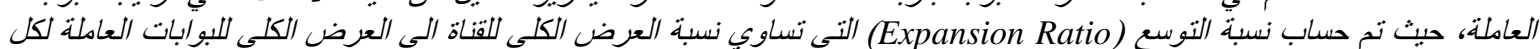

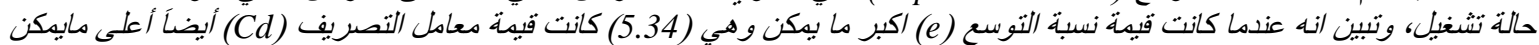

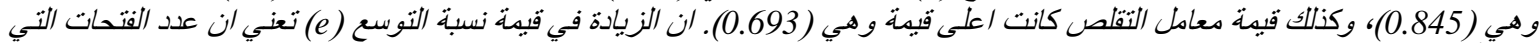

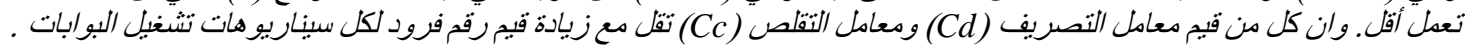

أكلمات الد/الهه :

بوابة متعددة الفتحات، نسبة التوسع، معامل التصريف، معامل التقلص. 